\title{
Conversação entre Abordagens da Estratégia em Organizações: Escolha Estratégica, Cognição e Instituição
}

\author{
Conversation between Approaches of Strategy in \\ Organizations: Strategic Choice, Cognition and Institution
}

\author{
Valéria S. da Fonseca* \\ Doutora em Engenharia de Produção pela UFSC. \\ Professora Adjunta do PPAD/PUCPR, Curitiba/PR, Brasil.
}

Clóvis L. Machado-da-Silva

Ph.D. em Estudos Organizacionais e Estratégia pela Michigan State University, EUA. Professor Titular do CEPPAD/UFPR e Professor do PMDA/UP, Curitiba/PR, Brasil.

* Endereço: Valéria S. da Fonseca

Pontifícia Universidade Católica do Paraná, Escola de Negócios, Programa de PósGraduação em Administração, Rua Imaculada Conceição, 1155, Bloco Acadêmico, $1^{\circ}$ andar, Prado Velho, Curitiba/PR, 80215-901.E-mail: vsf29@ hotmail.com

Este artigo foi originalmente publicado na Organizações \& Sociedade, v. 9, n. 25, Setembro/ Dezembro, 2002, pp. 93-110. 


\section{Resumo}

No presente trabalho pretendeu-se verificar qual o tratamento dispensado ao conceito de estratégia organizacional nas abordagens da escolha estratégica, cognitiva e institucional. Para tanto, delimitaram-se critérios de análise teóricos e metodológicos. A identificação desses critérios foi realizada de modo descritivo, a partir do exame dos pressupostos de cada abordagem focalizada. As descrições dos seus respectivos indicadores foram agrupadas em matrizes de conteúdo e analisadas por meio do uso do método comparativo. Os indicadores dos critérios teóricos foram as representações do indivíduo, da organização e do ambiente. O indicador do critério metodológico foi a dimensão de análise. Os resultados obtidos revelam variações significativas que configuram arranjos específicos de definição e tratamento dos elementos constitutivos da concepção de estratégia organizacional, em cada uma das abordagens analisadas.

Palavras-chave: estratégia organizacional; abordagem da escolha estratégica; abordagem cognitiva; abordagem institucional.

\section{Abstract}

This paper was written with the objective of checking on the treatment given to the concept of organizational strategy within each of the strategic choice, cognitive and institutional approaches. To carry out this objective, theoretical and methodological criteria were defined. The identification of these criteria was presented in a descriptive fashion, starting with the examination of the referential background for each approach. The descriptions of their respective indicators were grouped into content matrixes, and analyzed by the means of a comparative methodology. The indicators of the theoretical criteria were the representations of the individual, the organization and the environment. The indicator of the methodological criteria was the dimension of analysis. The results obtained reveal significant variations which configure specific arrangements of definition and treatment of the constitutive elements of conception of organizational strategy in each of the approaches under analysis.

Key words: organizational strategy; strategic choice approach; cognitive approach; institutional approach. 


\section{INTRODUÇÃO}

Em tempos de globalização, as organizações obrigam-se a definir novas prioridades e práticas a fim de enfrentar a acirrada competição doméstica e iniciar o intercâmbio com setores internacionais. Tais práticas são implementadas em direção ao atendimento da tendência de homogeneização determinada pela proposta de consolidação de um mercado global, em que comparações são incentivadas para o desenvolvimento de semelhantes decisões e ações, sobretudo de natureza estratégica.

Para tanto, traçam-se preceitos e receitas, divulgados e explorados à exaustão em livros, revistas, jornais, seminários, conferências, atividades de consultoria e, até mesmo, em trabalhos científicos dos mais variados campos de estudo. Nos estudos organizacionais, em particular, expressões como vantagens competitivas, competências essenciais, visão estratégica, entre outras, já são amplamente utilizadas, denotando, na ótica de Carrieri (1998), uma tentativa de enquadramento do saber, dos modos de pensar e de agir, que traduz a necessidade de as organizações definirem as estratégias conforme os padrões ditados pelo processo de globalização.

Acredita-se, porém, que tal circunstância pode estar longe de se concretizar à medida que, por força do excesso, se emprega no cotidiano o termo estratégia sem a adequada discriminação ou reflexão, o que só contribui para torná-lo cada vez mais difuso e impreciso. Além disso, a possibilidade de administração de mudanças estratégicas, salientada com freqüência na literatura especializada, parece nortear a idéia de modelagem das organizações em resposta às exigências do contexto globalizado, demonstrando que a abordagem da escolha estratégica ainda se impõe como discurso predominante. Como esclarecem Mintzberg, Ahlstrand e Lampel (1998), a despeito da acentuada queda sofrida pela área no início da década de 80 do século passado, investigações substanciais e de cunho mais explicativo, em associação com as circunstâncias do mercado, impulsionaram o seu renascimento com acréscimo de novos conteúdos, justificando, assim, a sua influência atual.

Diante dessas considerações, argumenta-se que a predominância da abordagem da escolha estratégica nos âmbitos da literatura e do cotidiano das organizações, além da imprecisão vocabular e conceitual em voga, impede a apreensão de aspectos importantes para o êxito na implementação de estratégias organizacionais, que emergem nas atuais circunstâncias de consolidação de um mercado global e 
são considerados, em outras abordagens, como a percepção e interpretação de pressões contextuais e a busca de legitimidade ambiental. É nessa direção que se pretendeu verificar qual o tratamento dispensado ao conceito da estratégia organizacional nas abordagens da escolha estratégica, cognitiva e institucional.

A partir de tal prerrogativa, estipularam-se critérios teóricos e metodológicos, cuja identificação foi efetuada de modo descritivo, com base no exame dos pressupostos de cada abordagem focalizada. As descrições dos seus respectivos indicadores foram agrupadas em matrizes de conteúdo e analisadas por meio do uso do método comparativo. Os indicadores dos critérios teóricos foram as representações do indivíduo, da organização e do ambiente expressos nas perspectivas em foco (Rouleau \& Séguin, 1995). O indicador do critério metodológico foi a dimensão de análise, que se revela na opção do pesquisador ao empreender uma investigação, pelo exame das propriedades estruturais do contexto dentro do qual o fenômeno em estudo acontece ou da definição que o ator realiza de tal situação (Astley \& Van de Ven, 1983). Os resultados obtidos na detecção e análise dos critérios selecionados permitiram distinguir o arranjo particular dos elementos constitutivos da concepção de estratégia organizacional nas abordagens da escolha estratégica, cognitiva e institucional, como se poderá verificar na sequiência deste trabalho.

A trajetória da evolução dos estudos organizacionais tem-se caracterizado pela eclosão de tensões, conflitos e controvérsias entre teorias, cuja diversidade e fragmentação resultantes acarretam intensas discussões. Se alguns pesquisadores consideram que tal pluralismo garante o acúmulo de conhecimentos consistentes, outros o encaram como sinal de iminente desordem e dissolução na área. No entanto, uma tendência já começa a se esboçar em torno da defesa da conversação entre diferentes abordagens, sugerindo a incorporação da diversidade como parte do processo de elaboração teórica, além de caminho promissor para o alcance de explicações mais completas da realidade organizacional (Reed, 1996).

Em concordância com esse argumento, sustenta-se que a relevância do presente trabalho reside na tentativa de suplementar o conhecimento existente sobre estratégia organizacional com a idéia de complementaridade entre concepções diferenciadas acerca dos fatores que afetam a sua formulação. As críticas efetuadas na literatura especializada à abordagem da escolha estratégica e a carência de investigações que promovam semelhante conciliação justificam a necessidade de se empreender estudos que desvendem outras lógicas de orientação. Futuras pesquisas poderão, assim, ampliar os seus limites e agregar contribuições significativas ao tema em pauta, ao incorporarem a esse discurso outros pontos de vista. 


\section{Estratégia Organizacional: Comparando Perspectivas}

Estratégia é uma das palavras-chaves da modernidade e nas últimas décadas transformou-se em conceito polêmico, que comporta diversas definições oriundas de perspectivas variadas de análise. Na abordagem da escolha estratégica acolhese o princípio da ação racional-instrumental, sob o qual formular uma estratégia representa optar por determinados objetivos e procedimentos, ligados a um conjunto de resultados deliberadamente traçados para a resolução de situações específicas. A sua delimitação envolve percorrer uma cadeia de meios e fins, a partir da maximização de informações, da alocação de recursos e do arranjo político, visando o desvio de ameaças ou o aproveitamento de oportunidades ambientais. Assim, a escolha é considerada o principal elo de ligação entre a organização e o ambiente (Andrews, 1965; Child, 1972; Miles \& Snow, 1978).

Não obstante, evidências empíricas têm apoiado a concepção de que a formação da estratégia também se configura como processo de cognição, eliciado pelos conteúdos e mecanismos que ocupam a mente dos dirigentes. Desse modo, veicula-se que os vieses cognitivos, a percepção e a interpretação de estímulos externos orientam a maneira de avaliar as informações advindas do ambiente, passível de ser decodificada por meio de mapas cognitivos. Com base nas proposições da abordagem cognitiva, tais pesquisas destacam a possibilidade de elementos ambientais serem subjetivamente avaliados (Huff, Narapareddy, \& Fletcher, 1990; Ranson, Hinings, \& Greenwood, 1980; Schwenk, 1988).

$\mathrm{O}$ ambiente, no mais das vezes reduzido a uma força geral e externa com a qual a organização tem de lidar para se manter em funcionamento, atraiu maior interesse com o surgimento do modelo de sistema aberto e, mais tarde, com a premissa de relação funcional entre características situacionais e atributos organizacionais, fixada pela teoria contingencial. Vislumbrado como mero conjunto de pressões técnicas e econômicas pelos adeptos da abordagem da escolha estratégica ou como conjunto de dimensões abstratas pelos partidários da abordagem cognitiva, o ambiente ganha real destaque somente no corpo de teorias contemporâneas, cujas idéias se estendem à geração de estratégias. Para Mintzberg et al. (1998) o ambiente assume o comando e deixa de ser um fator para se tornar o ator no palco da explicação dos fenômenos organizacionais. Entre essas novas perspectivas de análise, destaca-se a abordagem institucional em que o ambiente é visualizado como repositório de redes relacionais e de sistemas culturais, compostos por valores/ crenças e regras, que transmitem conceitos sobre modos apropriados de fazer e de agir. A conformação a tais fatores normativos garante suporte e legitimidade para a organização, e a sua reprodução, ao longo do tempo, 
conduz à convergência de estruturas e de estratégias no interior de um mesmo setor social. Logo, de acordo com essa abordagem, os princípios de eficiência e de competitividade de mercado são modelados dentro de uma realidade socialmente construída (DiMaggio \& Powell, 1983; Meyer \& Rowan, 1983; Scott, 1983; Scott \& Meyer, 1991).

Em face da breve exposição precedente, discorre-se, na seqüência, sobre a identificação e a comparação dos critérios teóricos e metodológicos utilizados pelos partidários das abordagens da escolha estratégica, cognitiva e institucional para a explicação da estratégia organizacional.

\section{RepresentaÇÃo do Indivíduo, da Organização e do Ambiente}

A ciência, observam Chanlat e Bedard (1996), conseguiu algumas vezes abalar a concepção narcisista de ocupação privilegiada do homem no cosmos e, diante de tais golpes, talvez uma das poucas especificidades ainda cabível ao gênero humano seja a capacidade de evocar formas racionais de pensamento. Conforme os gregos já salientavam, somente o homem pode emitir idéias fundamentadas na adesão explícita a regras, culminando em conclusões susceptíveis de julgamento pelos seus pares.

Os filósofos, em particular, se apegaram à noção do homem como ser racional, transformando-a em ideal de comportamento expresso em doutrinas como a do hedonismo ou convicção de que a ação se orienta, entre outros fatores, pelo atendimento de interesses pessoais (Gardner, 1996). Tal corrente parece haver fornecido subsídios para a construção do conceito de homem apregoado em diversos ramos do conhecimento, desde aquele sustentado pela escola clássica da economia ou pela escola da administração científica.

A visão do chamado homem econômico nos estudos organizacionais sugere que os indivíduos agem de modo calculista, motivados para o trabalho pela necessidade exclusiva de obtenção de recompensas econômicas equivalentes aos seus interesses. À medida que a organização se encarrega de fornecer a remuneração, eles são assim seres constantemente controlados e encarados como um tipo de recurso básico. A eficiência no desempenho das tarefas para o cumprimento dos objetivos organizacionais é enfatizada e qualquer manifestação de desagrado ou de moral reduzido é considerada uma restrição a ser superada por meio da adoção de procedimentos, tais como reestruturação de funções, modificação dos sistemas de incentivo e de controle ou promoção de treinamento. 
Tal cenário, que parece pressupor uma ótica dúplice de homem em um mesmo modelo, revela o posicionamento no topo da hierarquia somente daquele indivíduo capaz de definir os propósitos da organização e de coordenar as atividades dos demais, segundo a sua própria determinação, cujas funções básicas são planejar, organizar, gerenciar, dirigir e controlar. Ao formular uma estratégia, ele adota uma postura racional que se materializa na seleção da alternativa considerada mais adequada para o alcance de fins deliberadamente traçados. Em outras palavras, esse tipo de dirigente atua com base em cálculos utilitários de conseqüências (Simon, 1979).

Os pressupostos da abordagem da escolha estratégica espelham essa representação do indivíduo, sobretudo no que se refere ao papel do dirigente. Acredita-se que o gestor profissional de Chandler (1962), o estrategista de Andrews (1965), o administrador defensivo, prospector ou analítico de Miles e Snow (1978), bem como o executivo competitivo de Porter (1986) expressam imagens resgatadas da percepção do dirigente essencialmente como agente econômico. Juntas, tais imagens contribuem para compor o modelo de homem que de fato parece surgir da abordagem em foco: o detentor do poder organizacional de Child (1972).

O detentor do poder, à semelhança do homem econômico, atua no sentido de maximizar esforços para o estabelecimento dos cursos de ação estratégica, visando a atender aspirações objetivas. Ele também possui autonomia para coordenar as atividades e os rumos da organização e deliberar sobre eles, característica que o enquadra na categoria de agente. Assim, as suas atribuições englobam a escolha de domínios de produto e de mercado, de tecnologias apropriadas para a produção e distribuição dos produtos oferecidos, além da criação de um sistema de informações, de comunicação e de controle das operações, preparando a organização para ajustar-se ao ambiente (Child, 1972; Miles \& Snow, 1978).

Esse dirigente garante tais prerrogativas pela sua habilidade de controlar situações críticas ou de alocar recursos escassos. Ele integra um grupo que exerce influência por meio da capacidade de articular interesses pessoais e organizacionais, e, ocasionalmente, manipular forças internas e externas, conforme a sua avaliação das circunstâncias ambientais. Em outras palavras, é um agente econômico que propicia a ligação entre a organização e o ambiente, e se encontra em posição de efetuar escolhas estratégicas por fazer parte da coalizão dominante, que sobrepuja a atuação dos outros membros organizacionais.

Para Simon (1979), o homem econômico lida com o mundo real de maneira objetiva, procurando enfrentar toda a sua complexidade, o que lhe confere uma onisciência racional, destacada, principalmente, por economistas ortodoxos. 
Fatores como o entusiasmo por modelos matemáticos de decisão, decorrente da introdução de sistemas computacionais nas organizações, acentuaram a defesa de tal concepção.

Por outro lado, o advento do computador também revitalizou a realização de pesquisas sobre o aparelho cognitivo, assim como o desenvolvimento da teoria dos custos de transação obrigou os economistas a admitir a existência de racionalidades imperfeitas (Gardner, 1996; Knudsen, 1995). Questões dessa natureza permitiram direcionar o foco de análise para os arranjos de percepção presentes no contexto organizacional, levando à conseqüente aceitação de outro modelo de homem, com características análogas àquele designado por Simon (1979).

Subjacente à definição de homem administrativo, encontra-se a idéia de que os indivíduos são movidos no trabalho predominantemente por incentivos econômicos, mas se contentam com as possibilidades ao seu alcance. Eles interagem, compartilham valores e interesses, assumindo objetivos da organização, segundo o grau de identificação com grupos internos ou externos. Preocupamse em desempenhar com competência as tarefas relativas ao cargo que ocupam e, na posição de dirigentes, desenham estruturas e processos conforme percepções e interpretações compartilhadas com os demais membros organizacionais (March \& Simon, 1958; Simon, 1979).

O dirigente, nessa ótica, ao formular estratégias não dispõe de todas as informações necessárias e tampouco possui capacidade intelectual para lidar simultaneamente com grande quantidade delas, além de sofrer pressões de tempo. Desse modo, ao contrário do que se preconiza na visão de homem econômico, ele efetua escolhas sem condições de analisar todas as alternativas de solução e de antecipar os seus respectivos resultados. Em face de tal situação, procura formular um curso de ação satisfatório entre aqueles que conseguiu delimitar, a partir das suas percepções e experiências; portanto, o seu comportamento é intencional, mas limitadamente racional (Simon, 1979).

Tomando como base as premissas sustentadas na abordagem cognitiva, encontrase um conceito de indivíduo que se equipara à representação do homem administrativo. A distinção de vieses e mapas cognitivos, de esquemas interpretativos, além da explicação da relação entre ação e interpretação parecem refletir a absorção de um modelo de homem que atua dentro da organização como agente psicossocial, conforme captado na análise dos estudos de Giddens (1978), Ranson et al. (1980), Huff (1990), Laroche e Nioche (1994), entre outros autores.

Tal tipo de indivíduo é retratado como ser que apreende a realidade por meio de categorizações mentais, efetuadas para decodificar a conexão entre os seus 
componentes, e as utiliza para perceber e compreender situações e eventos, principalmente na ausência de certeza. Ele compartilha e renova o conjunto de significados resultante por meio da interação social, e os exterioriza na forma de valores/crenças e interesses. Na sua associação com grupos ocupacionais, sobretudo com aqueles localizados no topo da hierarquia, ele pode usar esses padrões cognitivos para propor operações e arranjos organizacionais e, quando bem-sucedido, consegue convertê-los em fonte de orientação para a conduta de outros indivíduos, obtendo influência dentro da organização. Logo, ele é portador de múltiplas racionalidades e, em face da necessidade de formular ações estratégicas, as emprega para contemporizar no esforço de busca de alternativas que conduzam à satisfação dos resultados. Na abordagem cognitiva, o decisor (agente psicossocial) parece ser assim vislumbrado como um indivíduo que se concentra somente nos aspectos percebidos como essenciais para solucionar o problema com o qual se defronta, originários de intenções e de modos de interpretação.

A exemplo do observado por Schneider e Angelmar (1993), na sua avaliação das pesquisas realizadas acerca da cognição nas organizações, pode-se subentender da descrição precedente que a cognição individual produz ação organizacional e, conseqüentemente, desempenho. Porém, imprimir qualquer direção causal a essa relação revela-se resposta precipitada, em face da idéia de reciprocidade entre ação e interpretação. A compreensão mais correta talvez proceda da constatação de Scott (1995) de que sistemas de significados compartilhados são tratados na abordagem cognitiva como facetas subjetivas e internas. Destaca-se, ainda, o fato de que a atenção dos seus adeptos se volta, predominantemente, para o entendimento dos conteúdos e dos processos mentais dos dirigentes.

Não obstante, a natureza do fenômeno da estratégia organizacional requer que se leve em conta argumentos que permitam vislumbrar o outro lado da equação, qual seja, a influência na ação dos sistemas de significados objetivos e externos ao indivíduo. Isso é proporcionado pela abordagem institucional.

A representação de indivíduo emergente dos princípios da abordagem institucional se assemelha àquela identificada na abordagem cognitiva, no que concerne ao mecanismo de desenvolvimento mental de padrões de significados e de interpretação e à maneira como são utilizados para a formulação da estratégia organizacional. Entretanto, conforme esclarecem DiMaggio e Powell (1991), a abordagem institucional enfatiza as propriedades de instituições, ampliando o foco de análise para além das conseqüências diretas de atributos e motivos individuais ou de escolhas autônomas. Vislumbra a ação como imersa (embedded) no contexto social, portanto impregnada pelo ambiente, o que torna a racionalidade 
dos indivíduos mais complexa do que aquela assumida pelo homem econômico e pelo ator psicossocial.

Em outras palavras, os partidários da abordagem institucional consideram que o comportamento individual é modelado por padrões criados e compartilhados na interação, mas incorporados na forma de normas e regras objetivas, cristalizadas na sociedade como concepções legitimadas sobre a maneira mais eficaz de funcionamento das organizações. Portanto, sob a orientação dos ditames sociológicos de Berger e Luckmann (1967), as investigações empreendidas, sobretudo por DiMaggio e Powell (1983), Meyer e Rowan (1983) e Scott (1983, 1995), implicitamente, transmitem um conceito de indivíduo enquanto ator social: um ser que assume um papel, ou identidade na ótica dos teóricos cognitivistas, cujas características são esboçadas de acordo com as expectativas de grupos externos sobre quem ele é e a maneira como deve enfrentar certas situações. Empregados com direitos e responsabilidades ou gestores com obrigação e capacidade de planejar, gerenciar, dirigir e controlar, configuram-se como tipos de atores desempenhando papéis socialmente construídos, dotados de diferentes conhecimentos e habilidades para exercer atividades organizacionais.

Nessa perspectiva, o indivíduo, na posição de dirigente, aprova (enact) mais do que age. No cotidiano da organização, ele confronta escolhas, mas estabelece alternativas, resultados, interesses e objetivos com base em critérios de referência definidos e consolidados por estruturas e sistemas sociais como o Estado, a indústria, associações profissionais, entre outros. Diante da incerteza ou da ambigüidade, em particular, procura obedecer às exigências governamentais, imitar estratégias formuladas pelos concorrentes ou implementar procedimentos adotados por redes profissionais, com o intuito de obter benefícios e recursos e, por conseguinte, angariar apoio e aceitação para a organização (DiMaggio \& Powell, 1983). Por exemplo, a posse de certificações da série ISO9000 revestese de importância ao possibilitar o alcance ou a manutenção da legitimidade ambiental. Por outro lado, no caso de ocorrência de conflito entre demandas internas e externas, o dirigente pode evitar ou desafiar a conformidade, mas sob o risco de ameaçar a sobrevivência da organização, como adverte Oliver (1991). Enfim, o conceito de homem na abordagem institucional se alicerça na idéia de construção socialmente modelada de um sistema comum de significados organizacionais.

Em síntese, como se observa na Tabela 1, na abordagem da escolha estratégica o indivíduo é visualizado como agente econômico: um ser racional, autônomo, integrante de uma coalizão dominante, que formula estratégias organizacionais a partir da avaliação das circunstâncias ambientais, visando à maximização dos resultados. Na abordagem cognitiva ele se manifesta como agente psicossocial, 
um ser portador de múltiplas racionalidades que define estratégias conforme percepções e interpretações compartilhadas da realidade, em busca de resultados satisfatórios. Já na abordagem institucional, considera-se que ele se comporta como ator social ao formular ações estratégicas com base nos significados atribuídos às regras de funcionamento das organizações, institucionalizadas na sociedade.

Tabela 1

Componentes da Representação do Indivíduo nas Abordagens em Foco

\begin{tabular}{|c|c|c|c|}
\hline Representação & $\begin{array}{c}\text { Abordagem da Escolha } \\
\text { Estratégica }\end{array}$ & Abordagem Cognitiva & $\begin{array}{l}\text { Abordagem } \\
\text { Institucional }\end{array}$ \\
\hline Indivíduo & $\begin{array}{l}\text { agente econômico } \\
\text { - ser racional, autônomo } \\
\text { - formulação de estratégias } \\
\text { conforme a avaliação das } \\
\text { circunstâncias ambientais, } \\
\text { visando à maximização } \\
\text { dos resultados }\end{array}$ & $\begin{array}{l}\text { agente psicossocial } \\
\text { - ser com múltiplas } \\
\text { racionalidades } \\
\text { - formulação de estratégias } \\
\text { conforme percepções e } \\
\text { interpretações } \\
\text { compartilhadas da } \\
\text { realidade, visando à } \\
\text { satisfação dos resultados }\end{array}$ & $\begin{array}{l}\text { ator social } \\
\text { - ser social } \\
\text { - formulação de estratégias } \\
\text { conforme significados } \\
\text { atribuídos às regras de } \\
\text { funcionamento } \\
\text { organizacional, } \\
\text { institucionalizadas na } \\
\text { sociedade }\end{array}$ \\
\hline
\end{tabular}

No que concerne à representação da organização, a análise da literatura permite constatar que tentativas de delimitação do conceito priorizam variadas instâncias para diferenciá-la de outros tipos de agrupamentos coletivos. Segundo Bastos (2000), existem pelo menos duas fontes de tensão associadas a tal empreendimento: a primazia das acepções de processo ou de entidade. Tais acepções referem-se aos aspectos, verbal ou substantivo, presentes no emprego cotidiano da palavra e em decorrência a prioridade posta nas ações dos integrantes ou nas dimensões da organização. Na prática, elas se entrelaçam, demonstrando que as diferenças são apenas de ênfase ou de formas de conceber a natureza da relação entre os atos individuais e as suas conseqüências.

A título de ilustração, Bastos (2000) constata que na matriz conceitual iniciada pelo movimento das relações humanas e aprimorada pela teoria comportamental, sobressai a instância processual do ato de organizar. Barnard (1938, p. 101), por exemplo, presume a existência de uma organização "quando (1) há pessoas aptas a se comunicarem entre si, (2) que desejam contribuir com a sua ação (3) para a realização de um propósito comum”.

Por sua vez, ancorando-se nas teorias estruturalista e contingencial, definições posteriores realçam a idéia de organização como entidade ou estrutura concreta, tangível e relativamente estável, cujos componentes 
respondem por parte do comportamento dos indivíduos que nela trabalham. Os conceitos resultantes salientam a combinação de três características organizacionais. Primeiro, a organização é concebida como coletividade orientada para o alcance de objetivos específicos. Tal procura é tida como intencional no sentido de que o seu cumprimento requer a coordenação entre relações funcionais e atividades desempenhadas de maneira sistemática. Os objetivos são específicos na extensão em que são definidos de forma clara, proporcionando critérios precisos para a seleção de alternativas de ação. Segundo, a organização exibe uma estrutura formal: um conjunto de rotinas, regras e procedimentos explícitos e hierarquicamente distribuídos. Terceiro, os estudiosos declaram que as operações organizacionais sofrem a influência de demandas ambientais.

A busca da representação de organização subjacente ao desenvolvimento da abordagem da escolha estratégica revela a predominância de um conceito de organização que parece assentar-se na concepção de entidade. Ao investigar o crescimento de grandes corporações norte-americanas, Chandler (1962) assume a instância substantiva para descrever a adoção de arranjos estruturais e estratégias de mercado no transcorrer do período formador do capitalismo moderno. Ao reportar-se aos problemas empresariais, de engenharia e administrativos com os quais os dirigentes têm de lidar para obter o alinhamento da organização com o ambiente, Miles e Snow (1978) enfatizam, sobretudo, exigências estruturais e tecnológicas. Child (1972), igualmente, concentra-se em tal acepção, ao situar nas etapas do exercício da escolha estratégica a delimitação de objetivos, a avaliação de expectativas e tendências ambientais, a implantação de um quadro de pessoal, de tecnologias e de um arranjo estrutural congruentes com a ação planejada, de acordo com as preferências dos integrantes da coalizão dominante da organização.

Acredita-se, portanto, que, sob o prisma da abordagem da escolha estratégica, a organização é vislumbrada como sistema racional, deliberadamente instituído para a consecução de objetivos específicos e susceptíveis de negociação por aqueles que detêm o poder de estabelecer os meios para atingi-los. Configura-se ainda como entidade produtiva e, assim, comercializa produtos ou serviços e se estrutura por atividades formalizadas e interdependentes, delineadas de acordo com requisitos tecnológicos e demandas do ambiente.

Em época recente, sinais crescentes de questionamento à perspectiva da organização como objeto conduziram ao resgate da acepção verbal, recolocando o indivíduo e os processos organizativos no centro das atenções. Tal posição foi fortalecida a partir da propagação da corrente do construcionismo social, responsável pela ênfase no efeito da ação na produção e reprodução das estruturas 
sociais (Giddens, 1978), o que contribuiu para despertar o interesse dos estudiosos pela influência da cognição na formulação de estratégias.

Gardner (1996) afirma que a ciência cognitiva visa a compreender a origem, a produção e o uso do conhecimento. Ao transpor tal idéia para o contexto da organização e combiná-la com a sua intrínseca instância funcional é possível supor, então, que para os cognitivistas ela se configura como um conjunto de reservas localizadas de conhecimento, que espelham o processo de apreensão da realidade por meio do uso de mecanismos mentais.

Por outro lado, há que se retomar a concepção de Giddens (1978): a estrutura é tanto meio como resultado da ação. Delinear tal compreensão conduz ao entendimento das práticas organizacionais de uma perspectiva mais dinâmica, enquanto produto de uma estrutura construída "para refletir e facilitar significados [a qual] descreve tanto o arcabouço prescrito quanto as configurações de interação realizadas e a extensão na qual eles são mutuamente constituídos e constitutivos" (Ranson et al., 1980, p. 3). Nesses termos, supõe-se que a estrutura da organização contempla duas faces interdependentes: (1) o arcabouço prescrito, correspondente à disposição formal de níveis hierárquicos, de regras e de procedimentos que normatizam as atividades; e (2) os padrões emergentes de interação, produto da percepção e da interpretação contínuas de regras e procedimentos na rotina diária da organização. $\mathrm{O}$ intercâmbio entre padrões normativos e padrões de interação é efetuado por meio da articulação entre valores/crenças e interesses, agrupados em esquemas interpretativos. Desse modo, estratégias de ação são formuladas mediante a leitura intersubjetiva e constante da estrutura e dos processos organizacionais, que permite a elaboração de uma resposta adequada às exigências ambientais (Hinings \& Greenwood, 1988; Ranson et al., 1980).

Nessa linha de raciocínio, emerge da abordagem ora focalizada uma representação da organização como um universo cognitivo, no qual os objetivos, a missão, a hierarquia de autoridade, as descrições de cargos e os procedimentos operacionais deixam de ser vistos como características concretas e se tornam artefatos simbólicos, projetados sobre uma base de conhecimentos, que refletem a maneira como os indivíduos percebem e interpretam a realidade organizacional. Tal universo é formado por reservas localizadas de conhecimento e artefatos simbólicos, criados por significados compartilhados, e mobilizados por atores em interação. Essa definição ratifica a afirmação de Hinings e Greenwood (1988) de que organizações são mais bem compreendidas em termos de padrões, ao invés da detecção exclusiva de conjuntos de dimensões.

A transição da ênfase no substrato substantivo para a instância verbal do conceito de organização também foi impulsionada sob a égide da tradição fenomenológica 
de Berger e Luckmann (1967) e de Weick (1987). Para Weick (1987), em particular, o termo organização contempla mais ordem, coordenação e sistematização do que se descobre na observação de pessoas trabalhando juntas em uma situação real. A ordem é transitória, imposta em meio da eclosão de interesses divergentes, competição profissional, rotatividade de empregados e recursos incertos. Logo, as atividades estão sujeitas à constante definição e redefinição, conforme acima explicitado e, por conseguinte, a organização não é uma entidade, mas um sistema social conectado, construído em interação.

Entre os institucionalistas, Meyer e Rowan (1983) encaram essa situação como oportunidade para o surgimento de organizações guiadas por regras e crenças, ou mitos racionais, institucionalizados em um campo de relações específico, que proporcionam ordem e significado às suas rotinas e arranjos estruturais, além de referência para escolhas e ações, sobretudo aquelas de natureza estratégica. Ainda assim, argumentam que a incorporação de concepções socialmente construídas pode colidir com critérios internos de eficiência, porque regras externas nem sempre fornecem orientações claras e precisas para a prática diária das atividades técnicas. Portanto, para manter a conformidade ambiental, a organização procura proteger a sua estrutura, efetuando ligações entre procedimentos administrativos e técnicos. Evitando a interdependência funcional, ela minimiza a possibilidade de ocorrência de inconsistências, disputas e conflitos, preserva a estabilidade das operações internas e garante o suporte ambiental. Afinal, ao demonstrar que atua de acordo com normas definidas e racionalizadas na sociedade, a organização obtém legitimidade, e assegura a sua sobrevivência e capacidade de expansão por meio da criação de oportunidades para alocar mais recursos e implementar inovações.

Cabe elucidar que na abordagem institucional não se exclui a possibilidade de existirem organizações predominantemente orientadas pela lógica da eficiência, nas quais se privilegia a natureza técnica do processo produtivo, conforme poderá ser observado na elaboração da representação do ambiente, apresentada na seqüência. No entanto, em sua essência, o conceito de organização, aqui transmitido, baseia-se no desencadeamento do processo de institucionalização e no seu efeito sobre a ação. Portanto, sob a ótica dessa abordagem, a organização parece ser vislumbrada como arena social, parte integrante de um sistema de relações de um campo específico, constituída por atividades padronizadas e conectadas, que refletem normas e regras sociais.

Em resumo, na abordagem da escolha estratégica, a organização é considerada um sistema racional composto por atividades formalizadas e interdependentes, estabelecidas de acordo com exigências tecnológicas e ambientais, e, deliberadamente, definidas para a consecução de objetivos específicos e 
negociáveis. Na abordagem cognitiva, a organização revela-se como universo cognitivo, formado por reservas localizadas de conhecimento e artefatos simbólicos criados por significados intersubjetivamente compartilhados e mobilizados na interação dos indivíduos. Na abordagem institucional, a organização é visualizada como arena social ou componente do sistema de relações de um campo específico, formado por atividades padronizadas e articuladas, que expressam normas e regras sociais (vide Tabela 2 ).

Tabela 2

Componentes da Representação da Organização nas Abordagens em Foco

\begin{tabular}{|c|c|c|c|}
\hline Representação & $\begin{array}{c}\text { Abordagem da Escolha } \\
\text { Estratégica }\end{array}$ & Abordagem Cognitiva & $\begin{array}{c}\text { Abordagem } \\
\text { Institucional }\end{array}$ \\
\hline & sistema racional & universo cognitivo & arena social \\
\hline \multirow[t]{2}{*}{ Organização } & - entidade produtiva & $\begin{array}{l}\text { - reservas localizadas de } \\
\text { conhecimento e artefatos } \\
\text { simbólicos }\end{array}$ & $\begin{array}{l}\text { - componente do sistema de } \\
\text { relações de um campo } \\
\text { específico }\end{array}$ \\
\hline & $\begin{array}{l}\text { - atividades formalizadas e } \\
\text { interdependentes, } \\
\text { delineadas por exigências } \\
\text { tecnológicas e ambientais, } \\
\text { e delibera damente } \\
\text { definidas para a } \\
\text { consecução de objetivos } \\
\text { específicos e negociáveis }\end{array}$ & $\begin{array}{l}\text { - significados } \\
\text { intersubjetivamente } \\
\text { compartilhados e } \\
\text { mobilizados por atores } \\
\text { em interação }\end{array}$ & $\begin{array}{l}\text { - atividades padronizadas e } \\
\text { frouxamente conectadas } \\
\text { - normas e regras sociais }\end{array}$ \\
\hline
\end{tabular}

A linha de raciocínio seguida até o momento exprime a idéia de que as organizações não são auto-suficientes: para continuarem a existir elas precisam conectar-se com o ambiente. As pesquisas inspiradas na teoria contingencial sugerem que, em uma esfera mais ampla, o ambiente é complexo, multifacetado e comum a todas as organizações, abarcando dimensões tecnológica, econômica, legal, cultural, demográfica, e assim por diante. Além de inserida em um ambiente geral, cada organização também lida com um segmento ambiental próximo e específico designado como ambiente de tarefa (Dill, 1958). Nele se encontram os indivíduos, grupos e instituições com os quais a organização se empenha em estabelecer relações de troca de recursos e de informações necessários para o alcance dos seus objetivos.

A análise demonstra que o conceito de ambiente adotado pela abordagem da escolha estratégica equivale ao ambiente de tarefa. Andrews (1965) concebe o modelo SWOT com base na admissão da influência do ambiente no processo de definição da estratégia organizacional, e assim propõe a avaliação dos aspectos internos à luz das circunstâncias externas. Miles e Snow (1978) apresentam 
uma tipologia na qual classificam estratégias de acordo com o alinhamento da organização a domínios de produto e de mercado, preconizando então um continuum de comportamento adaptativo às características da indústria, onde ela se situa. Porter (1986, p. 22) identifica as forças competitivas no ambiente que afetam a formulação de estratégias, referindo-se a fornecedores, concorrentes e compradores, e afirma que "o aspecto principal do meio ambiente da empresa é a indústria ou as indústrias em que ela compete". Child (1997) assume a predominância da idéia de ambiente de tarefa, quando desenvolveu o conceito de escolha estratégica, fundamentado no reconhecimento de que as estratégias definem a relação entre a organização e o ambiente. Em suma, o ambiente é representado como o mercado ou o segmento externo mais próximo à organização, que fornece as informações e os recursos técnicos e financeiros necessários ao seu desempenho.

É importante deixar claro que o conceito de ambiente de tarefa delineado na teoria contingencial corresponde àquele utilizado na abordagem da escolha estratégica somente no que se refere às suas características e não, necessariamente, no aspecto da relação entre a organização e o ambiente (processo de adaptação). Na teoria contingencial, parte-se do pressuposto de que o ambiente impõe restrições, coações, problemas e incertezas a serem enfrentados, uma vez que a sobrevivência da organização depende do ajuste a tais circunstâncias. Embora resquícios dessa idéia tenham permanecido nas investigações que deram início ao seu desenvolvimento, na abordagem da escolha estratégica sobressai a habilidade do dirigente em perceber as condições ambientais e revertê-las a favor da organização, por meio da formulação de ações estratégicas.

A abordagem cognitiva desafia a definição de práticas organizacionais dentro de uma teia de relações externas e substratos tangíveis. Para os proponentes dessa abordagem, o ambiente parece um rótulo conveniente para designar as atividades organizadas na sociedade, geradas por indivíduos que se esforçam intelectualmente para dar sentido aos seus atos. Nesse caso, não existem ameaças ou oportunidades ambientais concretas, apenas registros de ações, materiais e simbólicas, transformados em realidade coletiva. Nas palavras de Weick (1995), é a fabricação de sentido ou sensemaking.

Encontrar um sentido implica converter experiências e eventos em algo inteligível por meio do entendimento das relações e dos elementos que os constituem. Para tanto, empregam-se mapas cognitivos. De modo análogo ao uso de mapas cartográficos, os mapas cognitivos ressaltam a quais fatores o indivíduo confere maior atenção diante de um dado contexto. Retratam a situação tal como o indivíduo a percebe, o seu modo próprio de fazer as coisas, intermediado por 
vieses cognitivos e concretizado na utilização de esquemas interpretativos (Fiol \& Huff, 1992; Huff, 1990; Laroche \& Nioche, 1994; Weick, 1995).

Nessa perspectiva, o ambiente não assume o caráter de um objeto palpável ou um substrato com características e dimensões susceptíveis de delimitação e descrição, como o consideram os adeptos das outras abordagens em estudo. $\mathrm{O}$ ambiente aqui é fruto da percepção e da interpretação de redes relacionais externas, que ganham coerência e consistência na formulação de cursos de ação. Em outras palavras, os integrantes da organização não enxergam o ambiente, mas o constroem nas suas mentes na forma de padrões de significados e modos de interpretação intersubjetivos. Logo, acredita-se que ele é definido como domínio cognitivo ou repositório de padrões de significados criados por indivíduos e organizações em permanente troca de interpretações de eventos.

Uma questão implícita a essa representação e que ainda desperta certa polêmica é a demarcação das fronteiras entre a organização e o ambiente. Se na abordagem da escolha estratégica o ambiente é considerado uma espécie de fator limitante, de cujas flutuações a organização se deve proteger, e na abordagem cognitiva uma abstração mental, na teoria institucional ele surge como instância que se infiltra no cotidiano organizacional. Sob tal perspectiva de análise, as organizações estão imersas em ambientes, dos quais elas retiram e a eles transmitem modos adequados de ação, sobretudo de natureza estratégica. Especificamente, elas se encontram em setores sociais.

O setor social inclui as organizações que operam em um mesmo campo, para fabricar produtos e prestar serviços similares, e aquelas com as quais elas mantêm ligação em nível local, regional, nacional e internacional (Scott \& Meyer, 1991). Nesse sentido, os componentes de um setor social são interligados funcionalmente, mesmo quando localizados em posições geograficamente distantes, e as suas atividades se norteiam por lógicas diferenciadas e definidas de acordo com os ambientes técnico e institucional que os envolve.

O ambiente técnico é caracterizado por uma dinâmica de funcionamento que salienta a troca de bens ou serviços, de maneira que as organizações que nele se situam concentram as suas energias no controle e na coordenação dos processos produtivos, e são avaliadas pela eficiência em termos de quantidade e qualidade. O ambiente institucional, por sua vez, realça a elaboração e a difusão de regras e procedimentos aos quais as organizações se devem conformar para obter apoio e legitimidade contextual. Tais requisitos procedem do Estado, de redes profissionais e, até mesmo, de empresas concorrentes, que avaliam as organizações pela adequação do arranjo estrutural às suas exigências. Há ainda setores cujos componentes são envolvidos tanto pelo ambiente técnico como 
pelo ambiente institucional. Isso sugere que as organizações de um setor social estão sujeitas a pressões de caráter técnico e institucional, em diferentes proporções (DiMaggio \& Powell, 1983; Machado-da-Silva \& Fonseca, 1996; Scott \& Meyer, 1991).

As idéias precedentes revelam, portanto, que a definição das ações organizacionais sofre a influência de amplo conjunto de redes relacionais concretas. Nos termos do presente trabalho, o ambiente é então considerado pelos adeptos da abordagem institucional como setor social, ou campo externo que possui organizações fabricantes de produtos ou prestadoras de serviços similares, além de organizações responsáveis pela promulgação de regras de funcionamento organizacional e de alcance da legitimidade ambiental.

Em síntese, como se verifica na Tabela 3, na abordagem da escolha estratégica enfoca-se o ambiente de tarefa, considerando o mercado ou segmento externo mais próximo à organização, que proporciona as informações e os recursos técnicos e financeiros necessários ao seu desempenho. Na abordagem cognitiva, o ambiente é considerado um domínio cognitivo, ou repositório de padrões de significados, criados por indivíduos e organizações em permanente troca de interpretações de eventos. Na abordagem institucional, ele é representado como setor social, ou campo externo detentor de organizações que oferecem produtos e serviços semelhantes, e de organizações que estipulam regras de funcionamento e de obtenção da legitimidade contextual.

Tabela 3

Componentes da Representação do Ambiente nas Abordagens em Foco

\begin{tabular}{|c|c|c|c|}
\hline Representação & $\begin{array}{c}\text { Abordagem da Escolha } \\
\text { Estratégica }\end{array}$ & Abordagem Cognitiva & Abordagem Institucional \\
\hline \multirow{3}{*}{ Ambiente } & ambiente de tarefa & domínio cognitivo & setor social \\
\hline & $\begin{array}{l}\text { mercado ou segmento } \\
\text { externo mais próximo à } \\
\text { organização }\end{array}$ & $\begin{array}{l}\text { - repositório de padrões de } \\
\text { significados }\end{array}$ & - campo externo \\
\hline & $\begin{array}{l}\text { informações e recursos } \\
\text { técnicos e financeiros } \\
\text { necessários ao } \\
\text { desempenho da } \\
\text { organização }\end{array}$ & $\begin{array}{l}\text { padrões de significados } \\
\text { criados por indivíduos e } \\
\text { organizações em } \\
\text { permanente troca de } \\
\text { interpretações de eventos }\end{array}$ & $\begin{array}{l}\text { organizações que } \\
\text { oferecem produtos e } \\
\text { serviços semelhantes e } \\
\text { organizações que } \\
\text { estipulam regras de } \\
\text { funcionamento e de } \\
\text { obtenção da legitimidade } \\
\text { ambiental }\end{array}$ \\
\hline
\end{tabular}




\section{Dimensão de AnÁlise}

A inquirição das concepções delineadas sobre um fenômeno à luz de parâmetros teóricos também suscita derivações metodológicas. Dessa forma, a partir dos pressupostos e das descobertas analíticas sobre o indivíduo, a organização e o ambiente observa-se que a dimensão de análise focalizada pelos adeptos da abordagem da escolha estratégica é o ator, notadamente aquele que ocupa posições de poder, e as suas percepções objetivas da situação na qual a necessidade de definir estratégias se verifica. Referenciando-se no próprio conceito de escolha estratégica como processo no qual os membros da coalizão dominante decidem sobre cursos de ação, o raciocínio e a argumentação parecem voltados para clarificar o modo como esforços individuais são despendidos para atingir resultados organizacionais.

É nesse sentido que Chandler (1962) define estratégia, fundamentado no papel ativo exercido pelos indivíduos na modificação da estrutura. De maneira similar, Child (1972) defende a adoção da idéia de escolha estratégica, enfatizando a autonomia dos tomadores de decisão e a sua responsabilidade na promoção de conexões entre a organização e o ambiente. Miles e Snow (1978) atribuem o êxito dessa conexão à habilidade dos dirigentes em solucionar, simultânea e continuamente, os problemas empresariais, de engenharia e administrativos. Nessa mesma linha de raciocínio, Andrews (1965) associa todo o processo de formação de estratégias à figura dos dirigentes da organização, chegando a designá-los arquitetos do propósito organizacional.

Por sua vez, os partidários da abordagem cognitiva privilegiam a mesma dimensão de análise. A diferença se encontra no seu interesse em captar, além das percepções, as interpretações compartilhadas da situação na qual a necessidade de definir estratégias emerge. Tal interesse é explicável até mesmo pela preocupação em entender os conteúdos e os mecanismos mentais e a sua influência na formulação de ações e decisões, vista como o impulso para o desenvolvimento da própria abordagem.

Sob essa perspectiva, Makridakis (1990) enumerou generalizações e vieses cognitivos utilizados pelos dirigentes para simplificar o processo de resolução de problemas. Laroche e Nioche (1994) e Huff e colaboradores (vide Fiol \& Huff, 1992; Huff, 1990) procuraram identificar a maneira como os significados são atribuídos a um dado contexto por meio do uso de mapas cognitivos. Ranson et al. (1980) e Hinings e Greenwood (1988) investiram no entendimento da apreensão e elaboração de elementos simbólicos, explorando as noções de esquemas interpretativos, províncias de significados e arquétipos organizacionais. Importa 
destacar ainda o resgate, por parte de tais estudiosos, das idéias de Simon (1979) acerca das limitações da racionalidade e das características do homem administrativo, que deram margem à representação de indivíduo subjacente a essa abordagem.

Por último, os seguidores da abordagem institucional atentam para as propriedades estruturais dos contextos interno e externo dentro dos quais a estratégia é definida, guiados pela necessidade de aprofundar o conceito de ambiente e examinar o efeito na ação organizacional de facetas ambientais até então negligenciadas, como os valores/crenças e as regras socialmente constituídas. Nessa perspectiva, crescem em importância os conceitos de ambiente técnico e de ambiente institucional como facetas significativas da dimensão contextual, bem como a acepção de imersão social (embeddedness) das organizações, o que implica em permanente processo de mútua constituição na relação organização-ambiente. Logo, como se pode verificar na apresentação dos critérios teóricos, os estudos realizados por Meyer e Rowan (1983) e Scott (1983) concentram-se em torno de temáticas como o exame dos aspectos regulativos, cognitivos e normativos das instituições, a incorporação da legitimidade ambiental e a identificação de fontes potenciais de requerimentos institucionais.

\section{Considerações Finais}

A realização do presente trabalho foi orientada pela inquietação quanto à necessidade de construção de um quadro referencial mais apropriado para subsidiar a formulação de estratégias nas organizações. Para tanto, procurou-se ultrapassar o clássico esquema da escolha racional, ainda empregado com freqüência no desencadeamento de tal processo, e resgatar a influência de outros fatores como a cognição e as fontes externas de normalização e de legitimação.

Depreendeu-se da análise realizada que, movidos pela lógica utilitarista, os proponentes da abordagem da escolha estratégica mobilizaram esforços no sentido de reproduzir na época atual uma parte do cenário de combate ensejado pela origem militar do vocábulo estratégia. Imagens de subalternos disciplinados, oponentes derrotados, aliados cooptados e corrida para tomar a dianteira foram evocadas durante o exame dos seus pressupostos. $\mathrm{Na}$ prática organizacional, tal visão pode ser concretizada por meio da elaboração de seqüências de procedimentos para traçar alternativas de ação por indivíduos detentores do poder, a serem executadas por aqueles que ainda pretendem obtê-lo, para que objetivos sejam alcançados e o mercado conquistado. $\mathrm{O}$ sucesso alcançado acaba por incitar outras organizações a percorrerem o 
mesmo caminho, provocando a busca incessante por receitas e manuais que serão seguidos passo a passo (Carrieri, 1998).

Exemplos de aplicação desse raciocínio linear e racional na implementação de ações ofensivas ou defensivas são encontrados nos trabalhos de Andrews (1965) e de Child (1972), com a prescrição de modelos para a identificação de pontos fortes e pontos fracos, para a avaliação da posição da organização, visando ao aproveitamento de oportunidades e ao enfrentamento de ameaças ambientais. Destaca-se também Porter (1986) e a sua preocupação em projetar ações para neutralizar ou superar a concorrência no jogo competitivo, capturando a noção de estratégia como manobra, nos termos de Mintzberg (1987).

Em face de tais modelos, diferenças existentes entre organizações são esquecidas pelos dirigentes ou, pelo menos, apontadas como indicativo de ineficiência. Mintzberg et al. (1998) atestam que a análise SWOT se tem mostrado uma ferramenta muito conveniente nas mãos de consultores, convencidos da inutilidade de despender mais do que poucos dias de trabalho com a implementação de estratégias.

Alega-se, porém, que tais diferenças são susceptíveis de acarretar resultados distintos no uso das mesmas técnicas. Como afirma Granovetter (1985), o problema reside no fato de teorias dessa natureza operarem de acordo com uma concepção subsocializada de ação, o que torna os seus seguidores incapazes de reconhecer a variedade do mundo organizacional, que não se rende simplesmente à lógica universalizadora, baseada em noções de eficiência e de mercado. Acrescenta-se, ainda, a ausência de qualquer reflexão quanto à possibilidade de indivíduos perceberem de maneira diversa a mesma ocorrência ambiental, defendida pela abordagem cognitiva.

Ao salientar a interferência de mecanismos mentais na escolha intencional, a abordagem cognitiva ofereceu uma contribuição relevante para a construção do conhecimento sobre o tema, amenizando a exploração da conotação militar, além de suprir parte da demanda por ferramentas mais sensíveis aos aspectos envolvidos na formulação de estratégias organizacionais. O uso de mapas cognitivos, em particular, tem-se mostrado bastante proveitoso, tanto para explicar conceitualmente a maneira como os elementos da realidade são estruturados e categorizados em nível mental, como para subsidiar o desenrolar de processos organizacionais.

No entanto, o entusiasmo gerado pelas possibilidades de aplicação dos conceitos desenvolvidos pela abordagem cognitiva não se mostrou suficiente para arrefecer a ânsia por uma compreensão apurada do processo de delineamento de estratégias organizacionais, à medida que isso requer elucidar o vínculo entre a organização 
e o ambiente. Nessa perspectiva, a abordagem institucional, além de superar a tendência de vislumbrar a ação estratégica como uma simples conseqüência do ajustamento entre necessidades organizacionais e pressões ambientais, permitiu examinar essa relação sob duas bases reveladoras: a da reciprocidade e a da legitimação. Acredita-se que a idéia que melhor traduz a essência de tal conexão é a concepção de imersão social (embeddedness), lançada por Granovetter (1985) e acolhida pela abordagem institucional.

Encarar a organização como socialmente imersa no contexto ambiental pressupõe redirecionar o raciocínio no sentido de fora para dentro, transferindo o foco de análise do discernimento da eficiência ou não de estruturas e processos internos para a incorporação dos significados externos aos princípios de ação estratégica. Especificamente, assumir que as propriedades do nível macro da relação entre organização e ambiente geram efeitos recíprocos no nível micro da conduta organizacional. Logo, organizações sobreviventes a circunstâncias de incertezas e de competição podem não ser as mais eficientes na ótica dos adeptos da abordagem da escolha estratégica; mas elas persistem e são bemsucedidas, porque procuram se conformar a padrões normativos de legitimidade, consolidados no setor social, a partir da sua interpretação. Nesse caso, a definição de estratégias organizacionais torna-se predominantemente guiada pelo emprego de esquemas interpretativos, enquanto categorias cognitivas que condicionam a leitura interna e a conseqüente aceitação externa.

É sob esse prisma que as abordagens focalizadas no presente trabalho se complementam, fornecendo uma amostra da riqueza de possibilidades de estudos e de ação que o campo da administração estratégica oferece aos acadêmicos e aos profissionais atuantes em áreas associadas às atividades de organizações. A despeito das dificuldades inerentes a qualquer tentativa de conciliação entre abordagens fundamentadas em diferentes disciplinas do conhecimento, como a necessidade de compatibilizar linguagens e conceitos, os resultados até aqui encontrados revelam que tal conversação pode ser efetivada, ampliando-se o limite do que comumente se considera suficiente para explicar e executar as ações organizacionais.

Além disso, entende-se que, em tempos de globalização, já não cabe defender a fragmentação analítica quando o assunto é a formação de estratégias e, tampouco, a segmentação prática manifestada no uso de uma classificação hierárquica que trata o conceito em termos da divisão em estratégias corporativas, empresariais ou funcionais. A presente análise sugere que a estratégia é fenômeno único e organizacional, a cargo dos dirigentes, mas fruto da dinâmica de interação entre agentes internos e externos, envolvidos por circunstâncias econômicas, sociais e históricas específicas. Assim, a estratégia é fenômeno amplo e complexo capaz de moldar e de transformar as organizações. 


\section{ReferênCias Bibliográficas}

Andrews, K. R. (1965).

The concept of corporate strategy. Homewood, IL: Richard D. Irwin.

Astley, W. G., \&

Van de Ven, A. H. (1983).

Central perspectives and debates in organization theory. Administrative Science Quarterly, 28(2), 245-273.

Barnard, C. I. (1938).

The functions of the executive. Cambridge: Harvard University Press.

Bastos, A. V. B. (2000).

Organização e cognição: o que emerge desta interface? In S. B. Rodrigues \& M. P. Cunha (Orgs.), Estudos organizacionais: novas perspectivas na administração de empresas -uma coletânea luso-brasileira (pp. 173211). São Paulo: Iglu.

Berger, P. L., \&

Luckmann, T. (1967).

The social construction of reality: a treatise in the sociology of knowledge. New York: Doubleday Anchor Book.

Carrieri, A. P. de (1998, setembro). Pesquisa sobre estratégia: do discurso dominante a uma nova narrativa. Anais do Encontro Nacional da Associação Nacional de Pós-Graduação e Pesquisa em Administração. Foz do Iguaçu, PR, Brasil, 22.

Chandler, A. D., Jr. (1962).

Strategy and structure: chapters in the history of the american industrial enterprise. Cambridge: MIT Press.
Chanlat, A., \&

Bedard, R. (1996).

Palavras: a ferramenta do executivo. In J.-F. Chanlat (Coord.), O indivíduo na organização: dimensões esquecidas (3a ed., pp. 125-148). São Paulo: Atlas.

Child, J. (1972).

Organizational structure, environment and performance: the role of strategic choice. Sociology, 6(1), 1-22.

Child, J. (1997).

Strategic choice in the analysis of action, structure, organizations and environment: retrospect and prospect. Organization Studies, 18(1), 43-76.

Dill, W. R. (1958).

Environment as an influence on managerial autonomy. Administrative Science Quarterly, 2(4), 409-443.

DiMaggio, P. J., \&

Powell, W. W. (1983).

The iron cage revisited: institutional isomorphism and collective rationality in organizational fields. American Sociological Review, 48(2), 147-169.

DiMaggio, P. J., \&

Powell, W. W. (1991).

Introduction. In W. W. Powell \& P. J. DiMaggio (Eds.), The new institutionalism in organizational analysis (pp. 1-38). Chicago: The University of Chicago Press. 
Fiol, C. M., \&

Huff, A. S. (1992).

Maps for managers: where are we? where do we go from here? Journal of Management Studies, 29(3), 267285.

Gardner, H. (1996).

A nova ciência da mente: uma história da revolução cognitiva (2a ed.). São Paulo: EDUSP.

Giddens, A. (1978).

Novas regras do método sociológico. Rio de Janeiro: Zahar Editores.

Granovetter, M. (1985).

Economic action and social structure: the problem of embeddedness. American Journal of Sociology, 91(3), 481-510.

Hinings, C. R., \&

Greenwood, R. (1988).

The dynamics of strategic change. New York: Basil Blackwell.

Huff, A. S. (1990).

Mapping strategic thought. In A. S. Huff (Ed.), Mapping strategic thought (pp. 11-49). New York: John Wiley \& Sons.

Huff, A. S.,

Narapareddy, V., \&

Fletcher, K. E. (1990).

Coding the causal association of concepts. In A. S. Huff (Ed.), Mapping strategic thought (pp. 311325). New York: John Wiley \& Sons.

Knudsen, C. (1995).

The competence view of the firm: what can modern economists learn from Philip Selznick's sociological theory of leadership? In W. R. Scott
\& S. Christensen (Eds.), The institutional construction of organizations: international and longitudinal studies (pp. 135-163). London: Sage Publications.

Laroche, H., \&

Nioche, J.-P. (1994).

L'approche cognitive de la stratégie d'entreprise. Revue Française de Gestion, (99), 64-78.

Machado-da-Silva, C. L., \&

Fonseca, V. S. da (1996).

Competitividade organizacional: uma tentativa de reconstrução analítica. Organizações e Sociedade, 4(7), 97-114.

Makridakis, S. (1990).

Forecasting, planning, and strategy for the 21st century. New York: The Free Press.

March, J. G., \&

Simon, H. A. (1958).

Organizations. New York: John Wiley \& Sons.

Meyer, J. W., \&

Rowan, B. (1983).

Institutionalized organizations: formal structure as myth and ceremony. In J. W. Meyer \& W. R. Scott (Eds.), Organizational environments: ritual and rationality (pp. 21-44). London: Sage Publications.

Miles, R. E., \&

Snow, C. S. (1978).

Organizational strategy, structure, and process. New York: McGraw-Hill.

Mintzberg, H. (1987).

The strategy concept I: five ps for strategy. California Management Review, 30(1), 11-24. 
Mintzberg, H.,

Ahlstrand, B., \&

Lampel, J. (1998).

Strategy safari: a guided tour through the wilds of strategic management. New York: The Free Press.

Oliver, C. (1991).

Strategic responses to institutional processes. Academy of Management Review, 16(1), 145-179.

Porter, M. E. (1986).

Estratégia competitiva: técnicas para análise de indústrias e da concorrência. Rio de Janeiro: Campus.

Ranson, S.,

Hinings, B., \&

Greenwood, R. (1980).

The structuring of organizational structures. Administrative Science Quarterly, 25(1), 1-17.

Reed, M. (1996).

Organizational theorizing: a historically contested terrain. In S. R. Clegg, C. Hardy, \& W. R. Nord (Eds.), Handbook of organization studies (pp. 31-56). London: Sage Publications.

Rouleau, L., \&

Séguin, F. (1995).

Strategy and organization theories: common forms of discourse. Journal of Management Studies, 32(1), 101117.

Schneider, S. C., \&

Angelmar R. (1993).

Cognition in organizational analysis: who's minding the store? Organization Studies, 14(3), 347-374.
Schwenk, C. R. (1988).

The cognitive perspective on strategic decision making. Journal of Management Studies, 25(1), 41-55.

Scott, W. R. (1983).

The organization of environments: network, cultural, and historical elements. In J. W. Meyer \& W. R. Scott (Eds.), Organizational environments: ritual and rationality (pp. 155-175). London: Sage Publications.

Scott, W. R. (1995).

Contemporary institutional theory. In $\mathrm{W}$. R. Scott, Institutions and organizations (pp. 33-62). London: Sage Publications.

Scott, W. R., \&

Meyer, J. W. (1991).

The organization of societal sectors: propositions and early evidence. In W. W. Powell \& P. J. DiMaggio (Eds.), The new institutionalism in organizational analysis (pp. 108140). Chicago: The University of Chicago Press.

Simon, H. A. (1979).

Comportamento administrativo. Rio de Janeiro: FGV.

Weick, K. (1987).

Perspectives on action in organizations. In J. W. Lorsch (Ed.), Handbook of organizational behaviour (pp. 10-28). Englewood Cliffs, NJ: Prentice-Hall.

Weick, K. (1995).

Sensemaking in organizations. London: Sage Publications. 